\title{
THE INFLUENCE OF BACKWARD SWEEP ON AERODYNAMIC PERFORMANCE OF A 1.5-STAGE HIGHLY LOADED AXIAL COMPRESSOR
}

\author{
Song Huang \\ Institute of Engineering Thermophysics, \\ Chinese Academy of Sciences \\ University of Chinese Academy of Sciences \\ huangsong@iet.cn \\ Beijing, China
}

\author{
Chengwu Yang \\ Institute of Engineering Thermophysics, \\ Chinese Academy of Sciences \\ yangchengwu@iet.cn \\ Beijing, China
}

\author{
Shengfeng Zhao \\ Institute of Engineering \\ Thermophysics, Chinese \\ Academy of Sciences \\ zhaoshengfeng@iet.cn \\ Beijing, China
}

\author{
Mingyang Wang \\ Institute of Engineering \\ Thermophysics, Chinese \\ Academy of Sciences \\ wangmingyang@iet.cn \\ Beijing, China
}

\author{
Xingen lu \\ Institute of Engineering \\ Thermophysics, Chinese \\ Academy of Sciences \\ luxg@iet.cn \\ Beijing, China
}

\section{ABSTRACT}

As a degree of freedom in three-dimensional blade design of axial compressor, the sweep technique significantly affects aerodynamic performance of axial compressors. In this paper, the influence of backward sweep rotor configurations on aerodynamic performance of a 1.5-stage highly loaded axial compressor is studied by numerical simulation. The aim of this work is to improve understanding of flow mechanism of backward sweep on aerodynamic performance of a highly loaded axial compressor. A commercial CFD package is employed for flow simulations and analysis. The study found that backward sweep had little effect on peak efficiency of the 1.5-stage axial compressor. At the design rotational speed, compared with baseline, backward sweep rotor configurations reduce the blade loading near the leading edge but slightly increases the blade loading near the trailing edge in the hub region. As the degree of backward sweep increases, total pressure ratio and stall margin of the 1.5-stage axial compressor increase first and then decrease. Among different backward sweep rotor configurations, the $10 \%$ backward sweep rotor configuration has the highest stall margin, which is about $2.5 \%$ higher than that of baseline. This is due to the change of downstream stator incidence, which improves flow capacity near the hub region. At $60 \%$ rotational design speed, passage shock disappears. Backward sweep rotor configurations deteriorate stall margin of the compressor, but increase total pressure ratio and adiabatic efficiency when
\end{abstract}

flow rate is lower than that at peak efficiency condition. Therefore, it's necessary to consider flow field structure of axial compressors in the design process and use the design freedom of sweep to improve the aerodynamic performance.

\section{INTRODUCTION}

With the rapid development of turbomachinery technology, the design requirements of compressors are moving toward highly loaded, highly efficiency and highly stall margin. To meet above requirements, the sweep technique has been widely used in the design process of compressors. The concept of sweep was initially developed for aircraft wing to successfully reduce drag and flow losses. It was later discovered that the sweep technique has large impact on aerodynamic performance of axial compressors. Up to now, development of the sweep technique has gone through four stages: preliminary exploration of sweep concept, in-depth study of backward sweep technique, in-depth study of transonic compressor forward sweep technique, and in-depth study of subsonic compressor sweep technique (Ji et al., 2005). Wadia et al. (1997) studied the influence of sweep on transonic compressor and concluded that forward sweep can improve efficiency and stall margin of a transonic compressor. Hah et al. (1998) conducted a detailed study on the influence mechanism of sweep on position and structure of passage shock wave in a transonic compressor. It was considered that the shock surface was gradually perpendicular to the casing 
wall in the radial direction. The passage shock wave moved upstream for backward sweep rotors. In contrast, the passage shock wave moved downstream for forward sweep rotors. Denton and Xu (2002) later found that sweep had little effect on peak efficiency and pressure ratio, however, significant affecting stall margin of a transonic fan. Gallimore et al. (2002) first successfully reported that the hub and casing sweep and dihedral modifications to rotor blades in multistage compressor in the open literatures. The overall objectives of the designs were met: the multistage compressor increased efficiency with no significant loss in surge margin. Lu et al. (2015) found an optimized sweep stator design is beneficial for decreasing the stator loss at hub region and improving the aerodynamic performance of a multistage axial-flow compressor. However, Boyer et al. (1995) studied stall warning time demonstrated by backward sweep rotor and zero sweep rotor at different rotational speeds. The results indicated that backward sweep rotor exhibited more stall warning time than zero sweep rotor. Goswami et al. (2016) found that backward sweep increased stall margin and forward sweep increased the choked mass flow rate.

For subsonic axial compressors, the passage shock wave disappears. The effects of sweep mainly lay in radial redistribution of flow field structure. Ramakrishna et al. $(2009 ; 2010)$ studied the effect of forward sweep on subsonic axial compressor rotor. The result showed that downstream stator with sweep rotor showed higher static pressure recovery than that of stator with zero sweep rotor at near stall condition. Gümmer et al. (2000) studied sweep and dihedral effects in axial compressor stators and demonstrated that positive sweep and positive dihedral could reduce end wall losses and increase operating range on compressors. Ilikan et al. (2015) found that forward sweep and backward sweep do not significantly affect aerodynamic performance of a fan at the design flow rate in spite of the occurring modifications of the local blade pressure distribution. However, at low flow rate, forward sweep and backward sweep have positive and negative effects on the fan performance, respectively.

Although many scholars have conducted extensive research on the sweep technique, the influence of sweep technique on aerodynamic performance of highly loaded axial compressor in different operating conditions such as transonic and subsonic is not deeply understood. Many scholars studying sweep in subsonic and transonic compressors have found that forward sweep in the tip region of a compressor rotor increases the stability of the tip region. This is supported by (Passrucker et al.,2003; Sun, S. et al.,2019). However, there is a controversy about the effect of backward sweep also can increases the stall margin of axial compressors in different operating conditions via means of matching the blade loading of the infinitesimal compressor along span over the stable operation range. This is supported by (Boyer et al.,1995; Ji et al.,2005). Based on the background, this paper aims at studying the influence of different backward sweep rotor configurations on the aerodynamic performance of a 1.5-stage highly loaded axial compressor at design rotational speed and $60 \%$ design rotational speed by numerical simulations, revealing the flow mechanism of different backward sweep rotor configurations.

\section{INVESTIGATED COMPRESSOR AND DEFINITION OF SWEEP}

The compressor under investigation in this study was a 1.5stage highly loaded axial compressor (Yang et al.,2015). It was designed and tested by in Laboratory of Light-duty Gasturbine, Institute of Engineering Thermophysics, Chinese Academy of Sciences, as shown in Figure 1. The compressor was designed to produce a pressure ratio of 1.72 at the designed mass flow rate. The compressor consists of 31 inlet guide vanes, 36 rotor blades and 59 stator vanes. Key aerodynamic and geometrical parameters of the compressor are presented in Table 1.

A variety of ways have been used to define sweep in the open literatures. In this paper, the definition of chord-wise sweep of Gallimore et al. (2002) was adopted, as shown in Figure 2. A parametric study was performed by changing the backward sweep length. The objectives was to obtain a physical understanding of the influence of sweep on aerodynamic performance of the 1.5-stage highly loaded compressor. Five different backward sweep rotor configurations were numerically studied. The position of rotor hub blade section was unchanged. The rotor tip blade section was moved along tip chord in the direction of flow. The moving distance was $5 \%, 10 \%, 15 \%, 20 \%, 25 \%$ tip chord length. Each blade section from the hub to the tip was translated linearly.

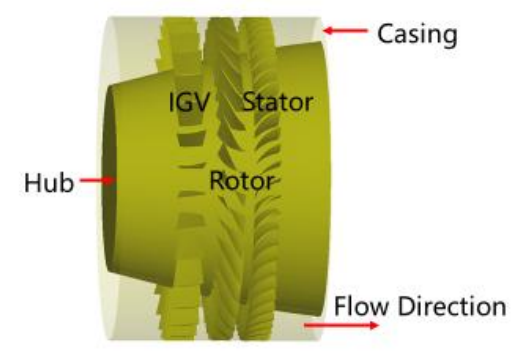

Figure 1 Compressor schematic diagram

\section{Table1 Key aerodynamic and geometric parameters of the 1.5-stage axial compressor}

\begin{tabular}{cc}
\hline Parameters & Values \\
\hline Design mass flow rate $(\mathrm{kg} / \mathrm{sec})$ & 4.5 \\
Design rotational speed $(\mathrm{rpm})$ & 25000 \\
Design pressure ratio & 1.72 \\
Design efficiency & 0.865 \\
Design tip speed $(\mathrm{m} / \mathrm{s})$ & 361 \\
Casing diameter $(\mathrm{mm})$ & 276 \\
Rotor tip clearance $(\mathrm{mm})$ & 0.2 \\
Inlet hub-tip radius ratio & 0.72 \\
Blade numbers & $31,36,59$ \\
Tip stage loading coefficient & 0.46 \\
\hline
\end{tabular}




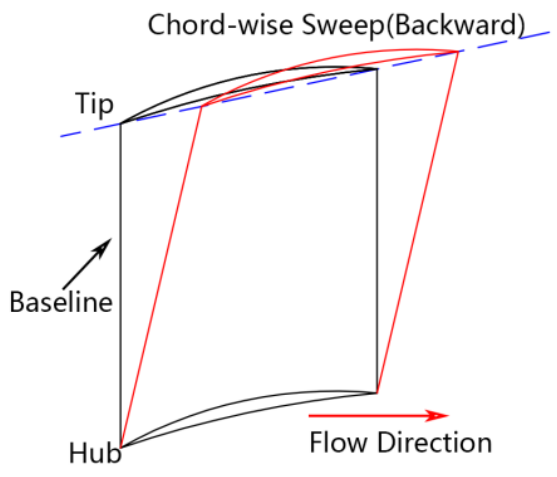

Figure 2 Definition of sweep

\section{NUMERICAL METHODS}

Three-dimensional steady numerical simulation and flow analysis was carried using the commercial code EURANUS. This code is an integral part of the software package NUMECA FINE. The one-equation Spalart-Allmaras turbulence model was used for the calculations. The Reynolds-averaged Navier-Stokes equation method is still the most widely used approach in industrial CFD due to the computational cost and the design schedule. The spatial treatment of Reynolds-averaged Navier-Stokes equation was performed using Jameson's cell-centered explicit finite volume. Time integration was performed using a four steps Runge-Kutta configuration. To speed up convergence to steady state, local time stepping, residual smoothing and multi-grid techniques were all applied. In the computation, the fluid is air modelled as a perfect gas. At the inlet boundary, uniform standard total pressure and total temperature with axial flow direction were imposed. At the subsonic outlet, the average static pressure was applied. At solid boundaries, i.e. hub, blade and casing surfaces, adiabatic non-slipping condition were imposed. A single blade passage was used for the calculations, using periodic boundaries to account for the number of blade passages. A Mixing plane was chosen for the rotor-stator frame change interface. The convergence global root mean square residual was set to $1 \times 10^{-6}$ to ensure the correct simulation results, the difference between the inlet and outlet calculation mass flow rate was less than $0.01 \%$. All the numerical simulations were started at choked condition and then marched towards near stall condition with gradual increase of the average outlet pressure. The predicted near stall point was judged to be the last stable condition prior to the oscillation in flow parameters and numerical divergence with increasing iteration numbers.

Blade geometry creation and grid generation for the 1.5stage axial compressor were conducted by using commercial software NUMECA AUTOGRID 5. The gird topology of different sweep configurations is the same. Due to almost similar characteristics for each blade row, the grid topology of the rotor was described in detail. Multi-block structured grids with hexahedral elements were used in the simulation. Around blade surfaces, the $\mathrm{O}$ grids were generated to improve the orthogonality, whereas $\mathrm{H}$ grids were used at the inlet, in the passage, and at the outlet, as shown in Figure 3. The distance between the first grid cell and the solid wall was set as $1 \times 10^{-6}$ meter to meet the need of the solid wall $\mathrm{y}^{+}<3$ for all computations.

In order to check the grid independence, three different meshes from 1.6 million nodes to 3 million nodes were selected. Figure 4 compared the data measured from the experiments and the results from numerical calculation for different meshes of the 1.5-stage axial compressor at 100\% design rotational speed. The abscissas represented the dimensionless mass flow, which were normalized by the choked mass flow. It can be seen that total pressure ratio in the numerical calculations were slightly higher than the experimental value, but adiabatic efficiency values were lower than the experimental value The discrepancy of the efficiency mainly due to the simulation fails to predict the total temperature distribution at different conditions, which is similar to the Rotor 37 in many report (Dalbert et al.,1995; Chima, et al.,1998; Beheshti et al.2004). When the mesh number of nodes was more than 2.3 million $(\mathrm{M})$, the total pressure ratio and adiabatic efficiency almost remain unchanged. It meant that the grid sensitivity can be eliminated when the number of nodes was 2.3 million. Therefore, the number of nodes of 2.3 million was suitable for calculation in order to reduce computation resource, the numerical model selected in this paper satisfied the calculation accuracy requirements and could be used for predict aerodynamic performance and analyse internal flow mechanism of the 1.5stage highly loaded axial compressor.

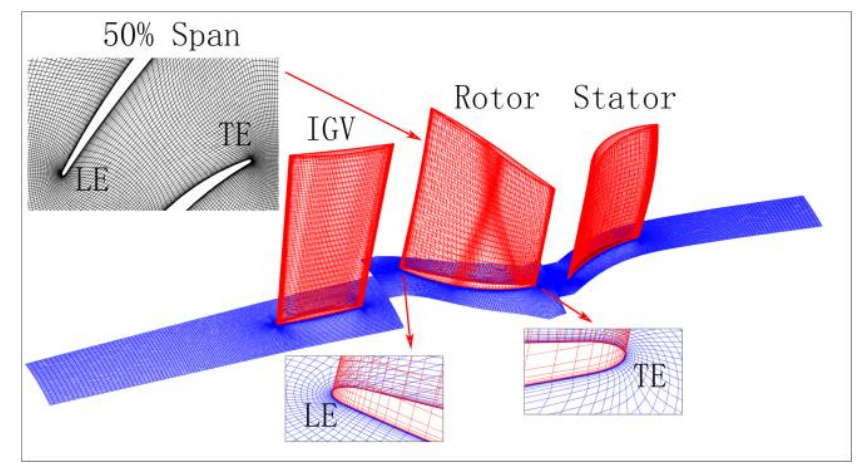

Figure 3 Grid for the 1.5-stage axial compressor

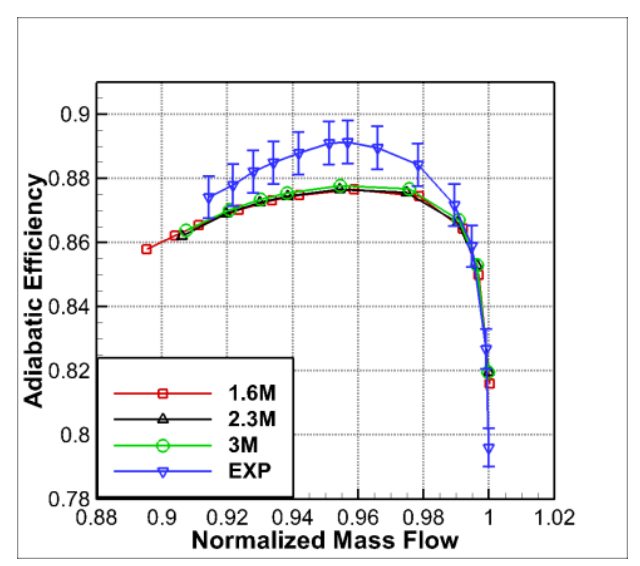




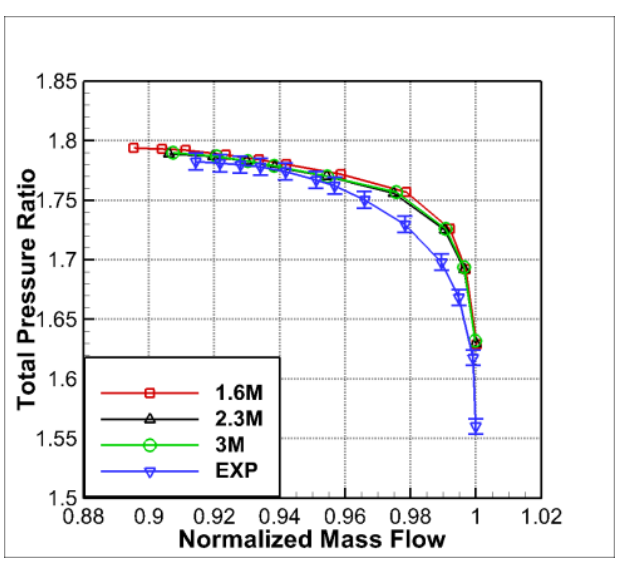

Figure 4 Computational and experimental compressor aerodynamic performance map

\section{RESULTS AND DISCUSSION \\ Flow mechanism at design rotational speed}

The compressor aerodynamic performance map for different backward sweep rotor configurations at design rotational speed is presented in Figure 5. As the degree of backward sweep increases, the total pressure ratio of the 1.5stage axial compressor increases first and then decreases, and they are always higher than zero sweep configuration, as seen in Figure 5. This is in contrast to an infinitely long sweep aerofoil configuration where the total pressure ratio decreases with the degree of backward sweep increases. The span-wise flow structure caused by backward sweep rotor configurations is modified by the hub and casing surfaces, which leads to a change in aerodynamic performance as the degree of backward sweep increases (Hah et al.1998). The figure also indicates that backward sweep has little effect on peak efficiency of the 1.5-stage axial compressor. The aerodynamic performance differences among different backward sweep rotor configurations increases with the decrease of mass flow rate.

To quantitatively analyse the compressor stability, the stall margin is defined as follows (Beheshti et al.2004):

$$
\mathrm{SM}=\left(\frac{\pi_{\mathrm{ts}} * m_{\mathrm{d}}}{\pi_{\mathrm{td}} * m_{s}}-1\right) \times 100 \%
$$

where $\pi_{t d}, m_{d}, \pi_{t s}$, and $m_{s}$ correspond to total pressure ratio at design point, mass flow rate at design point, total pressure ratio at near stall point and mass flow at near stall point, respectively. It can be seen from the Figure 6, as the degree of backward sweep increases, the stall margin increases first and then decreases. Under a certain range of backward sweep, stall margin is better than that of baseline, but when the backward sweep exceeds a certain value, stall margin deteriorates rapidly, which is lower than that of baseline. Among different backward sweep rotor configurations, the $10 \%$ backward sweep rotor configuration has the highest stall margin, which is about $2.5 \%$ higher than that of zero sweep rotor configuration.
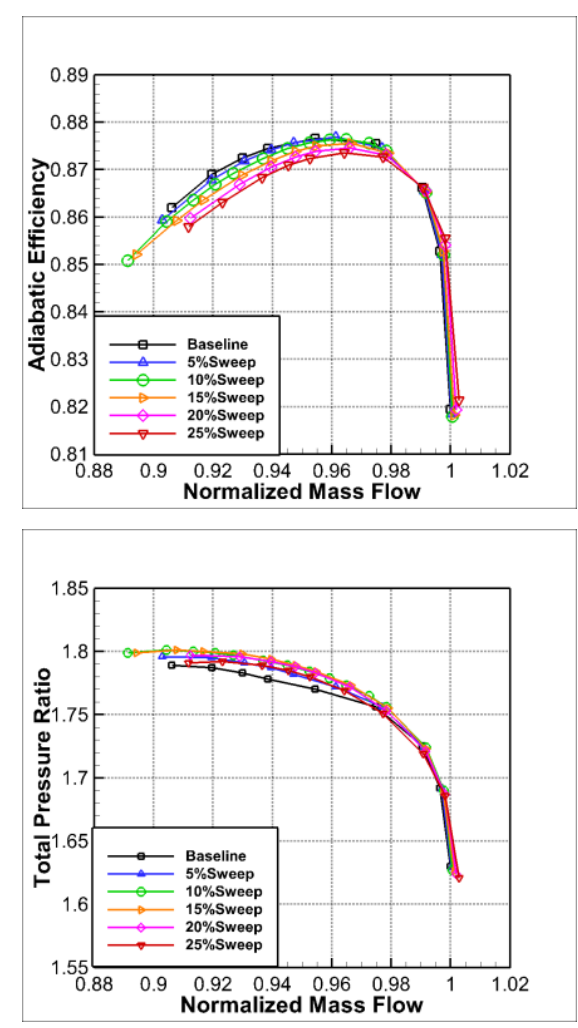

Figure 5 Compressor aerodynamic performance map at design rotational speed

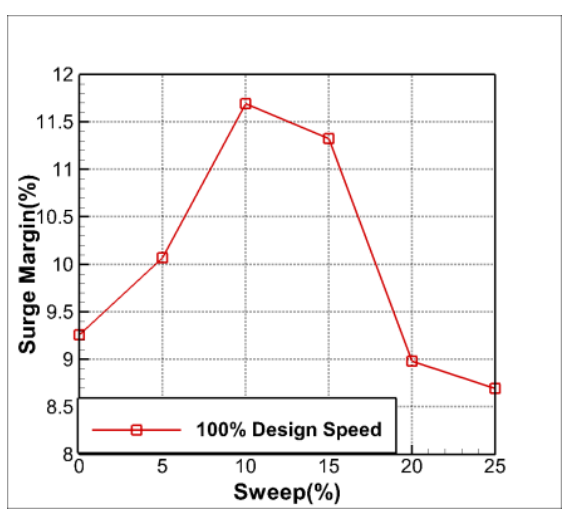

Figure 6 Stall margin for different sweep configurations at design rotational speed

The 10\% backward sweep rotor configuration is selected to analyse the flow mechanism of backward sweep rotor configurations improving the stall margin of the compressor. The stage is at the same normalized mass flow value of the near stall point of baseline. For baseline stator, the suction surface appears a wide range separation region from the stator hub up to about 50\% span height. Absolute Mach number contour for baseline and 10\% sweep configuration in 25\% span of the stator is plotted in Figure 7. It can be seen that there is a clear open separated flow in the rear part of suction surface for the baseline at near stall point, while the separated flow for $10 \%$ backward sweep rotor configuration decreases, as shown in region A in Figure 7. The reason for backward sweep improves stable operation range of the 1.5-stage axial compressor may be due to the improvement of flow capacity near the hub region of stator. Since translating the blade 
sections changes the distance between backward sweep rotor and downstream stator. Hence, the stage matching has been justified. For instance, decreasing gap between rotor and downstream stator has effects in terms of flow mixing, pressure loss and incidence as received by the stator.

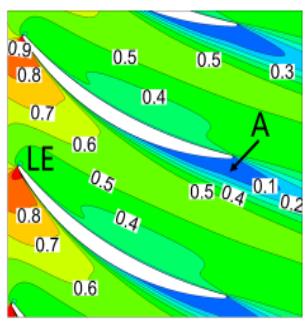

Baseline

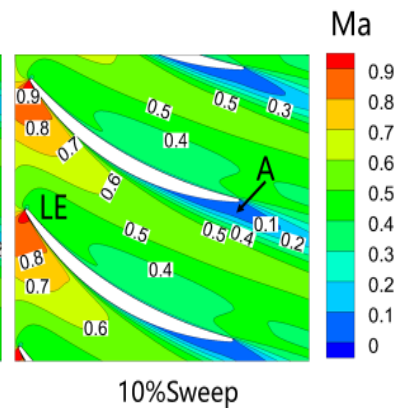

Figure 7 Absolute Mach number contour for baseline and $10 \%$ sweep configuration in $25 \%$ span

The span-wise distribution of stator inlet swirl angle for baseline and $10 \%$ sweep rotor configuration is shown in Figure 8 . The axial location of the plot is $10 \%$ of the axial chord length upstream of the stator leading edge. Note that the plot shows that stator inlet swirl angle for the $10 \%$ sweep rotor configuration is lower than that of baseline below $60 \%$ span. It indicates that sweep affects the flow structure inside the rotor, causing the stator incidence closer to the design value. Thereby, it significant improves the mass flux (density $\mathrm{x}$ axial velocity) of downstream stator from $10 \%$ span to $60 \%$ span as shown in Figure 9. The stability of the 1.5-stage compressor improves.

Isentropic Mach number distribution for the baseline and $10 \%$ sweep configuration on $5 \%$ span of the rotor blade surface is shown in Figure 10. It can be seen from the Figure 10, compared with baseline, the blade loading from the leading edge up to $20 \%$ chord length significantly decreases and the blade loading in the remaining portion of the aerofoil slightly increases for backward sweep configuration. And it also can be seen that the position of passage shock wave moves downstream for $10 \%$ sweep configuration, as indicates by the blue arrow. Therefore, the blade loading and passage shock wave together results in less blockage near the hub region, as shown in Figure 9.

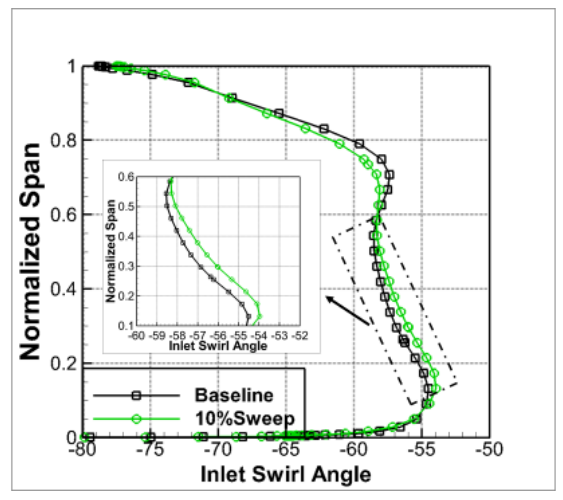

Figure 8 Stator inlet swirl angle for baseline and $10 \%$ sweep configuration

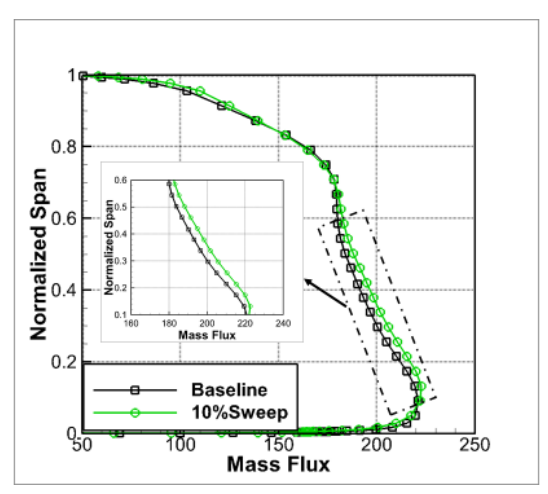

Figure 9 Stator inlet mass flux for baseline and 10\% sweep configuration

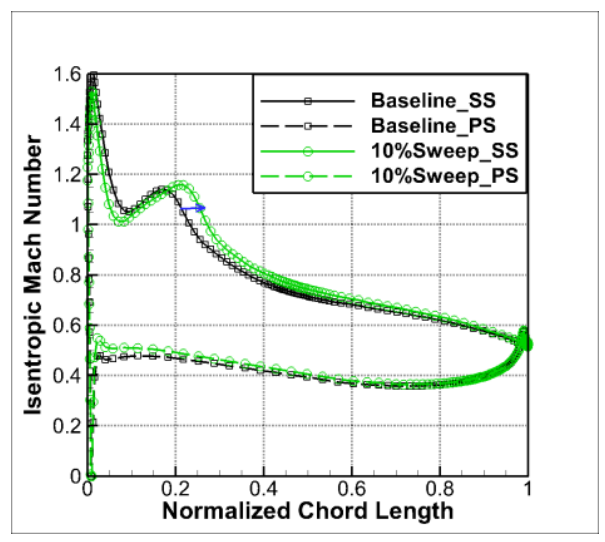

Figure 10 Isentropic Mach number for baseline and $10 \%$ sweep configuration on $5 \%$ span

However, at design rotational speed, when the degree of backward sweep is large, the stall margin of the compressor drops rapidly due to the rapid deterioration of the flow flied in the tip region. Figure 11 compares that relative Mach number for baseline and $25 \%$ sweep configuration in $95 \%$ span of the rotor. The stage is at the same normalized mass flow value of the near stall point of $25 \%$ sweep configuration. It can be seen that compared with that of the baseline, the intensity of passage shock wave for $25 \%$ sweep configuration is stronger. A wide low-speed region is observed mainly due to tip leakage flow, not for suction wake-related separation, as shown in region $\mathrm{A}$ in Figure 11. The wide low energy region, which brings high aerodynamic losses and results in severe flow blockage near the tip region, thus finally causes stall.

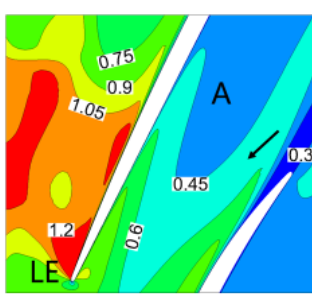

Baseline

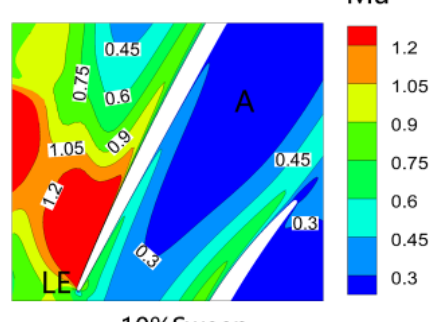

$10 \%$ Sweep
Figure 11 Relative Mach number contour for baseline and $25 \%$ sweep configuration in $95 \%$ span 
Trajectory of tip leakage flow originated from leading edge in rotor for baseline and 25\% sweep configuration is plotted in Figure 12. It can be seen that streamline of the $25 \%$ sweep configuration obvious divergence after passage shock wave compared with that of the baseline. The tip region appears in a larger range low-speed region than that of baseline, thereby blocking tip passage. Figure 13 compares that isentropic Mach number distribution for baseline and $25 \%$ sweep configuration on $95 \%$ span of the rotor blade surface. It can be seen that compared with baseline rotor, the blade loading before $25 \%$ chord length increases due to passage shock wave. Thereby, backward sweep rotor configurations affect the radial transportation of the boundary layer fluid through span-wise matching the blade loading, causing the boundary layer flow to shift toward the tip near the trailing edge with the centrifugal force. This is supported by (Govardhan et al.,2007; Cui et al.2016). And as tip blade loading near the leading edge increases, the pressure difference between suction surface and pressure surface increases; hence, the tip leakage flow rate through tip clearance increases. The interaction of passage shock wave and tip leakage flow causes stall margin of the 1.5-stage axial compressor decreases. In summary, a large degree of backward sweep configuration is severely detrimental to the aerodynamic performance near rotor tip region of the compressor, especially on stall margin, which is needed to be avoided in the design process of the axial compressor.

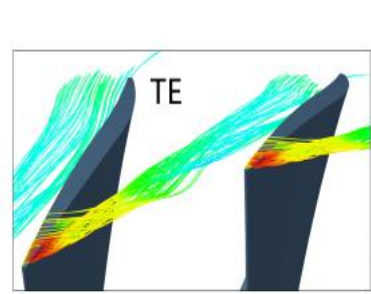

Baseline

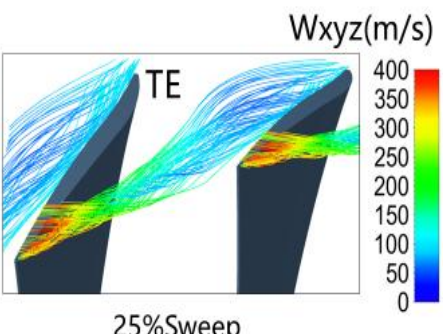

$25 \%$ Sweep
Figure 12 Tip Leakage flow originated from leading edge for baseline and $25 \%$ sweep configuration

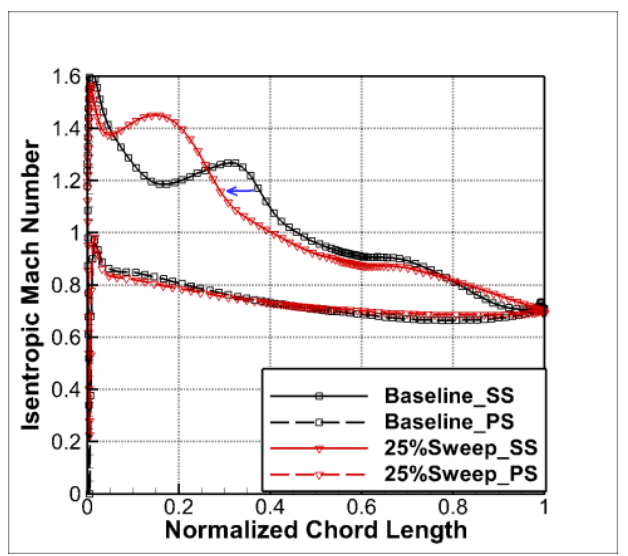

Figure 13 Isentropic Mach number for baseline and $25 \%$ sweep configuration on $95 \%$ span
Flow mechanism at $\mathbf{6 0} \%$ design rotational speed

At $60 \%$ design rotational speed, the passage shock wave disappears. The influence mechanism of sweep on the compressor is different from design rotational speed. The aerodynamic performance for different backward sweep rotor configurations at $60 \%$ design rotational speed is shown in Figure 14. It can be seen that backward sweep has little effect on peak efficiency of the 1.5-stage axial compressor at $60 \%$ design rotational speed. However, unlike the design rotational speed, the adiabatic efficiency and total pressure ratio increases as the degree of backward sweep increases when flow rate is lower than that at peak efficiency condition.

It can be seen from the Figure 15 that at $60 \%$ design rotational speed, the stall margin for different sweep configurations are always lower than that of baseline, but stall margin is about twice as mach as that at the design speed, which is enough large. And as the degree of backward sweep increases, the stall margin gradually decreases.
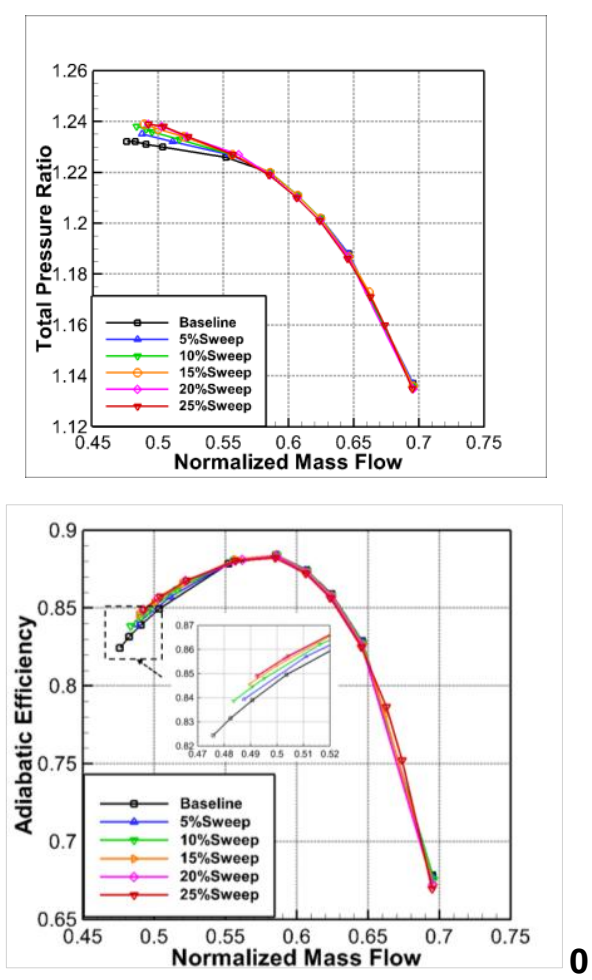

Figure 14 Compressor aerodynamic performance map at $60 \%$ design rotational speed

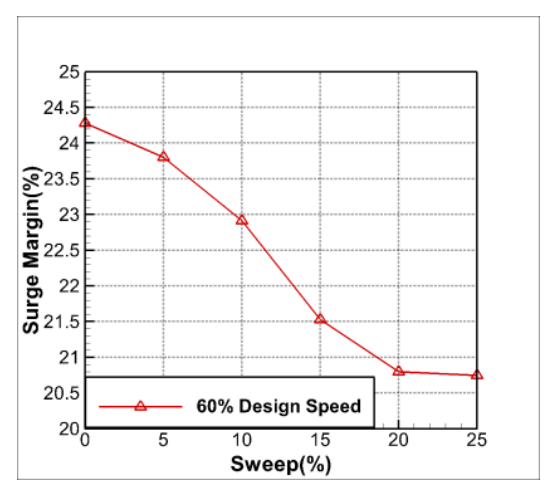

Figure 15 Stall margin for different sweep configurations at $60 \%$ design rotational speed 
To analyse the intrinsic mechanism of backward sweep configurations at $60 \%$ design rotational speed, relative Mach number contour for different sweep configurations in $98 \%$ span is plotted in Figure 16. The stage is at the same normalized mass flow value of the near stall point of $25 \%$ sweep configuration for all the cases. It can be seen that as the degree of backward sweep increases, the low velocity zone in the blade passage quickly increases, as shown in region $\mathrm{A}$ in Figure 16 .Thereby, the flow capacity in tip region significantly deteriorates. For $25 \%$ sweep configuration, the rotor is more likely to stall compared with baseline.

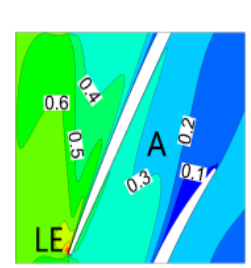

Baseline

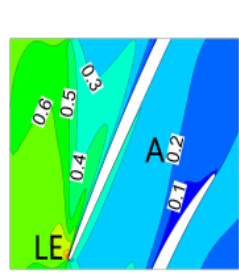

$10 \%$ Sweep

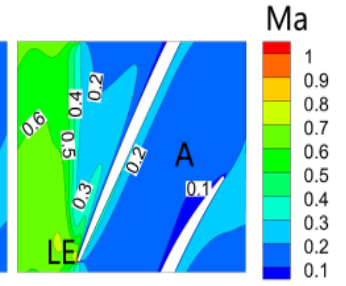

$25 \%$ Sweep

\section{Figure 16 Relative Mach number contour for different sweep configuration in $98 \%$ span}

Figure 17 compares the span-wise distribution of rotor inlet swirl angle for different sweep configurations. It can be seen that as the degree of backward sweep increases, the rotor inlet swirl angle above approximately 60\% span increases. According to the literature (Chang et al. 2015), backward sweep affects the redistribution of the flow parameter along circumference and span, which in turn produces a smaller meridional velocity and a larger circumferential velocity than those of the baseline. Thereby, the incidence of incoming flow increases as the degree of backward sweep increases, causing an increase in the blockage zone near the tip region. It also found that the blade loading near tip region hardly changes and the separation region near the suction surface moves downstream as the degree of backward sweep increases. Thus we can infer that tip flow capacity deteriorates mainly due to the variation of incidence rather than the blade loading and disappeared passage shock wave. At $60 \%$ design rotational speed, the main factor restricting the stable operation range of the 1.5stage compressor is the low energy flow in tip region rather than separation flow on suction surface.

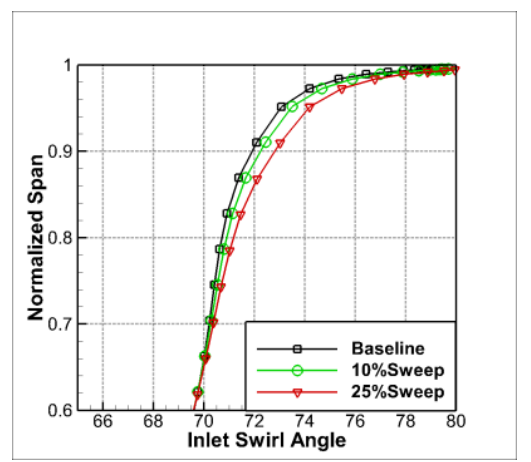

Figure 17 Rotor inlet swirl angle for different sweep configurations at $60 \%$ design rotational speed
Considering aerodynamic performance for different backward sweep configurations at the design rotational speed and $60 \%$ design rotational speed, the $10 \%$ sweep configuration shows higher stall margin at the design rotational speed and higher efficiency and total pressure ratio at $60 \%$ design rotational speed than baseline, which means better aerodynamic performance than baseline. This is to be proven by further experiments. The type of stall and poststall behaviour of the compressor are for further study.

\section{CONCLUSIONS}

Results of the detailed numerical simulation with different backward sweep rotor configurations are presented. The backward sweep rotor configurations affect passage shock wave, blade loading, tip leakage flow, boundary layer and blade row interactions, et al. In short, it's necessary to fully consider the flow field structure of axial compressors in the design process and use this design freedom of sweep to improve the aerodynamic performance. Conclusions are summarized as following:

1) At the design rotational speed, as the degree of backward sweep increases, the peak efficiency of the 1.5-stage highly loaded axial compressor hardly changes, however, the stall margin increases first and then decreases. The $10 \%$ backward sweep rotor configuration has the stall margin of about $2.4 \%$ higher than that of baseline. This is due to backward sweep rotor configuration reduces the blade loading near the leading edge but slightly increases the blade loading near the trailing edge in rotor hub region, which changes downstream stator incidence and improves the flow capacity near the hub region.

2) At the design rotational speed, when the degree of backward sweep is large, the intensity of passage shock wave near rotor tip region increases and the position of the passage shock wave moves upstream. The passage shock wave and tip leakage flow together results in severe flow blockage near the tip region, thus the stall margin deteriorates and should be avoided in the design process.

3) At the $60 \%$ design rotational speed, the passage shock wave disappears. The blade passage is almost full of subsonic flow. As the degree of backward sweep increases, peak efficiency hardly changes, but the total pressure ratio and adiabatic efficiency increases when flow rate is lower than that of peak efficiency condition. Due to the increase of rotor angle of attack, flow capacity deteriorates in the tip region and the stall margin of the compressor decreases.

\section{NOMENCLATURE}

$\begin{array}{ll}\pi & \text { pressure ratio } \\ \text { SM } & \text { stall margin } \\ \text { LE } & \text { leading edge } \\ \text { TE } & \text { trailing edge } \\ \text { PS } & \text { pressure surface } \\ \text { SS } & \text { suction surface } \\ \text { EXP } & \text { experiment } \\ \text { Wxyz } & \text { Magnitude of relative velocity } \\ \text { Ma } & \text { Relative Mach number } \\ \text { m } & \text { Mass flow rate }\end{array}$




\section{SUBSCRIPTS}

$\begin{array}{ll}\mathrm{S} & \text { near stall point } \\ \mathrm{d} & \text { design point } \\ \mathrm{t} & \text { total }\end{array}$

\section{ACKNOWLEDGMENTS}

This work is supported by National Natural Science Foundation of China with project No. 51606187, 51876202.

\section{REFERENCES}

[1] Ji L., Chen J., Lin F. (2005). Review and understanding on sweep in axial compressor design. ASME Turbo Expo 2005: Power for Land, Sea, and Air. American Society of Mechanical Engineers, 177-185. doi:10.1115/GT2005-68473

[2] Wadia A. R., Szucs P. N. (1997). Crall D W. Inner workings of aerodynamic sweep. ASME International Gas Turbine and Aeroengine Congress and Exhibition. American Society of Mechanical Engineers. doi:10.1115/97-GT-401

[3] Denton J. D., Xu L.(2002). The effects of lean and sweep on transonic fan performance. ASME Turbo Expo 2002: Power for Land, Sea, and Air. American Society of Mechanical Engineers, 23-32. doi:10.1115/GT2002-30327

[4] Hah C., Puterbaugh S. L., Wadia A. R. (1998). Control of shock structure and secondary flow field inside transonic compressor rotors through aerodynamic sweep. ASME 1998 International Gas Turbine and Aeroengine Congress and Exhibition. American Society of Mechanical Engineers. doi:10.1115/98-GT-561

[5] Gallimore, S. J., Bolger, J. J., Cumpsty, N. A., Taylor, M. J., Wright, P. I., \& Place, J. M. (2002). The Use of Sweep and Dihedral in Multistage Axial Flow Compressor BladingPart I: University Research and Methods Development. Journal of Turbomachinery, 124(4), 521-532. doi: 10.1115/gt2002-30328

[6] Gallimore S. J., Bolger J. J., Cumpsty N. A., et al. (2002). The use of sweep and dihedral in multistage axial flow compressor blading - part II: low and high-speed designs and test verification. Journal of turbomachinery 124(4), 533-541. doi: $10.1115 /$ gt 2002-30329

[7] Hanan, L., \& Li, Q. (2016). Analysis and applicat ion of a new type of sweep optimization on cantilevere $\mathrm{d}$ stators for an industrial multistage axial-flow compress or. Proceedings of the Institution of Mechanical Enginee rs, Part A: Journal of Power and Energy, 230(1), 44-62. doi:10.1177/0957650915607389

[8] Boyer K. M., King P. I., Copenhaver W. (1995).Stall inception in single-stage, transonic compressors with straight and sweep leading edges. Journal of Propulsion and Power 11(6), 1363-1366. doi:10.2514/3.23980

[9] Goswami S. N., Govardhan M. (2016). Effect of Sweep on Performance of an Axial Compressor With Casing Grooves. ASME Turbo Expo 2016: Turbomachinery Technical Conference and Exposition. American Society of Mechanical Engineers. doi:10.1115/GT2016-56045

[10] Ramakrishna P. V., Govardhan M. (2009). Study of sweep and induced dihedral effects in subsonic axial flow compressor passages - part I: design considerations_changes in incidence, deflection, and streamline curvature. International Journal of Rotating Machinery.doi: 10.1155/2009/787145

[11] Ramakrishna P. V., Govardhan M. (2010). Numerical study of the stagger angle effects in forward sweep axial compressor rotor passages. ASME Turbo Expo 2010: Power for Land, Sea, and Air. American Society of Mechanical Engineers, 443-453. doi:10.1115/GT2010-23160

[12] Gümmer, V., Wenger, U., \& Kau, H. P. (2001). Using Sweep and Dihedral to Control Three-Dimensional Flow in Transonic Stators of Axial Compressors. Journal of Turbomachinery, 123(1), 40-48.doi:10.1115/2000-GT-0491

[13] Ilikan, A. N., \& Ayder, E. (2015). Influence of the Sweep Stacking on the Performance of an Axial Fan. Journal of Turbomachinery, 137(6), 061004. doi: 10.1115/1.4028767

[14] Passrucker H., Engber M., Kablitz S.,Hennecke D. K. (2003). The Effect of Forward Sweep in a Transonic Compressor Rotor. Proceedings of the IMECHE Part A Journal of Power and Energy 217(41), 357-365. doi:10.1243/095765003322315414

[15] Sun, S., Wang, S., Chen, S., Tao, C., Cai, L., \& Chen, J. (2019). The impact of various forward sweep angles on the performance of an ultra-high-load low-reaction transonic compressor rotor. Applied Thermal Engineering, 150, 953966. doi: 10.1016/j.applthermaleng.2019.01.045

[16] Yang C., Lu X., Zhang Y., et al. (2015). Numerical investigation of a cantilevered compressor stator at varying clearance sizes. ASME Turbo Expo 2015: Turbine Technical Conference and Exposition. American Society of Mechanical Engineers.doi:10.1115/GT2015-42124

[17] Beheshti, Behnam H., et al. "Parametric Study of Tip Clearance - Casing Treatment on Performance and Stability of a Transonic Axial Compressor." Journal of Turbomachinery126.4 (2004): 527-535.doi:10.1115/GT200453390

[18] Dalbert, P., \& Wiss, D. H. (1995, June). Numerical transonic flow field predictions for NASA compressor rotor 37. In ASME 1995 International Gas Turbine and Aeroengine Congress and Exposition. American Society of Mechanical Engineers doi:10.1115/95-GT-326

[19] Chima, R. V. (1998). Calculation of Tip Clearance Effects in a Transonic Compressor Rotor. Journal of Turbomachinery, 120(1), 131-140. doi:10.1115/96-GT-114

[20] Cui W., Xiang X., Zhao Q., et al. (2016). The effect of sweep on flowfields of a highly loaded transonic rotor. Aerospace Science and Technology,71-81. doi:10.1016/j.ast.2016.08.002

[21] Govardhan, M., Kumar, O. G. K., \& Sitaram, N. (2007). Computational study of the effect of sweep on the performance and flow field in an axial flow compressor rotor. Proceedings of the Institution of Mechanical Engineers, Part A: Journal of Power and Energy, 221(3).doi:315-329. 10.1243/09576509JPE374

[22] Chang, H., Zhu, F., Jin, D., \& Gui, X. (2015). Effect of blade sweep on inlet flow in axial compressor cascades. Chinese Journal of Aeronautics, 28(1).doi:103-111. 10.1016/j.cja.2014.12.023 